УДК 681.51:622.73

\title{
КОМПЬЮТЕРНАЯ МОДЕЛЬ ПРИНЯТИЯ РЕШЕНИЙ ПО РЕКОНФИГУРАЦИИ СТРУКТУРЫ ТЕХНОЛОГИЧЕСКОЙ СИСТЕМЫ ИЗМЕЛЬЧЕНИЯ РУДЫ
}

\author{
Баласанян Сейран Шамирович', \\ seyran@sunicom.net \\ Геворгян Эрмине Михайловна', \\ hermine79@rambler.ru \\ 1 Капанский филиал Национального политехнического университета Армении,
Армения, 3307, г. Капан, ул. Багаберд, 28.
}

Актуальность исследования обусловлена необходимостью повышения надежности и эффективности функционирования технологической системы измельчения руды путем введения структурной избыточности.

Цель: обоснование необходимости повышения эффективности функционирования технологической системы измельчения руды путем введения структурной избыточности (резервных связей), определение наилучшей структуры резервных связей между измельчительными агрегатами и рациональной стратегии их использования, построение математической модели принятия решений по реконфигурации (перестроении) структуры технологической системы измельчения руды при отказах ее оборудования в виде дерева решений, разработка компьютерной модели принятия решений по реконфигурации структуры технологической системы измельчения руды.

Объект: технологическая система измельчения руды Зангезурского медно-молибденового комбината (Армения).

Методы: метод дерева решений (метод мягких вычислений), имитационное моделирование.

Результаты. В результате имитационных экспериментов с компьютерной модели технологической системы измельчения руды определена наилучшая структура резервных связей между измельчительными агрегатами и рациональная стратегия их использования, с применением которых построена математическая модель принятия решений по реконфигурации структуры технологической системы измельчения руды (при отказах ее оборудования) в виде дерева решений. На основе этой модели разработана компьютерная модель, позволяющая при изменении работоспособности измельчительных агрегатов своевременно выбрать наилучшую для данной сложившей отказовой ситуации структуру и режим работы каждого агрегата, независимо от квалификации и опыта оператора. Благодаря применению этой модели оператор полностью освобождается от обязанностей лица, принимающего решения. Разработанная компьютерная модель включена в состав специального программного обеспечения автоматизированной системы управления технологическим процессом измельчения руды Зангезурского медно-молибденового комбината (Армения).

Ключевые слова:

Измельчение руды, отказ, имитационное моделирование, дерево решений, реконфигурация, структурная избыточность.

\section{Введение}

Измельчение руды является важнейшим технологическим процессом рудоподготовки, непосредственно предшествующим конечному процессу флотации руды и в значительной мере предопределяющим его эффективность [1-4]. Как показывает опыт эксплуатации обогатительных фабрик, эффективность флотации заметно снижается в результате ухудшения выходных характеристик технологической системы измельчения руды (ТСИР) вследствие отказов ее оборудования [5-9]. В связи с этим вопросы обеспечения надежности и эффективности функционирования ТСИР приобретают особую важность.

Одним из возможных способов повышения эффективности функционирования ТСИР является введение структурной избыточности, т. е. резервных связей между измельчительными агрегатами (ИА), которые могут быть использованы для реконфигурирования (перестроения) структуры системы при отказах ее оборудования с целью рационального использования работоспособных агрегатов. Данная работа посвящена определению наилучшей структуры резервных связей между ИА и рациональной стратегии их использования, а так- же разработке на ее основе компьютерной модели принятия решений по реконфигурации структуры ТСИР Зангезурского медно-молибденового комбината (ЗММК, Армения).

\section{Содержательное описание нормального} функционирования ТСИР

ТСИР ЗММК (рис. 1) состоит из 21 мельницы шарового измельчения, 3 мельниц самоизмельчения, 6 двуспиральных классификаторов типа 2КСН-2.4, 10 односпиральных классификаторов типа КСН-2.0, 11 блоков гидроциклонов $\varnothing 750$ мм, 12 восьмидюймовых грунтовых насосов типа ГрАК 350/40, 10 двенадцатидюймовых грунтовых насосов типа ГрАК 1600/50, 24 систем смазки.

Цикл шарового измельчения включает 1 шаровую мельницу 1-й стадии типа МШР $3200 \times 3100$ мм, 2 шаровые мельницы 2-й стадии типа МШЦ - 3200×3100 мм стандартного размера, и 18 удлиненных шаровых мельницы типа МШР $3200 \times 3800 \mathrm{Mm}$.

Мельницы со своими системами смазки и классификаторами или блоками гидроциклонов составляют измельчительные агрегаты (ИА), которые вместе с грунтовыми насосами входят в состав из- 
мельчительных комплексов (ИК), работающих по схеме двухстадийного измельчения при сопряжении ИА 2:1 или 1:1 (ДИК (2:1) или ДИК (1:1)).

Измельчительные агрегаты $\mathrm{A}_{1}, \mathrm{~A}_{2}, \mathrm{~A}_{3}, \mathrm{~A}_{4}, \mathrm{~A}_{5}$, $\mathrm{A}_{6}, \mathrm{~A}_{7}, \mathrm{~A}_{8}, \mathrm{~A}_{11}, \mathrm{~A}_{13}, \mathrm{~A}_{16}, \mathrm{~A}_{17}$ работают по схеме двухстадийного измельчения при сопряжении мельниц $2: 1$, т. е. две мельницы 1-й стадии работают с одной мельницей 2-й стадии. Измельчительные агрегаты $\mathrm{A}_{9}, \mathrm{~A}_{10}, \mathrm{~A}_{14}, \mathrm{~A}_{12}, \mathrm{~A}_{20}, \mathrm{~A}_{21}, \mathrm{~A}_{22}, \mathrm{~A}_{23}, \mathrm{~A}_{24}$ и агрегаты самоизмельчения $\mathrm{AC}_{1}, \mathrm{AC}_{2}, \mathrm{AC}_{3}$ работают по схеме двухстадийного измельчения при сопряжении мельниц 1:1 (одна мельница 1-й стадии работает с одной мельницей 2-й стадии).

Руда из параболического бункера и бункера дробленой руды крупностью $<16$ мм подается на измельчение в шаровые мельницы 1-й стадии измельчения с разгрузкой через решетку. Разгрузка шаровых мельниц 1-й стадии измельчения агрегатов $\mathrm{A}_{1}, \mathrm{~A}_{2}, \mathrm{~A}_{3}, \mathrm{~A}_{4}, \mathrm{~A}_{8}, \mathrm{~A}_{10}$ поступает в двуспиральные классификаторы $\varnothing 2400 \mathrm{~mm}$, а разгрузка мельниц 1-й стадии агрегатов $\mathrm{A}_{17}, \mathrm{~A}_{16}, \mathrm{~A}_{21}, \mathrm{~A}_{22}$ и 2-й стадии агрегатов $\mathrm{A}_{9}, \mathrm{~A}_{10}$ поступает в односпиральные классификаторы $\varnothing 2000$ мм. Мельница измельчительного агрегата $\mathrm{A}_{13}$, в отличие от остальных мельниц 1-й стадии, работает в замкнутом цикле с гидроциклоном $\varnothing 750$ мм с непосредственным питанием восьмидюймовым грунтовым насосом. Все шаровые мельницы 2-й стадии ИА работают по замкнутой схеме с грунтовым насосом и батареей гидроциклонов, причем мельницы агрегатов $\mathrm{A}_{9}, \mathrm{~A}_{11}, \mathrm{~A}_{20}, \mathrm{~A}_{23}$ 2-й стадии измельчения одновременно подпитываются рудой из бункеров дробленой руды, что позволяет им при отказе или ремонте мельниц 1-й стадии работать в одностадийном режиме $(1: 0)$. Слив классификаторов и разгрузка мельниц 2-й стадии объединяются и поступают в зумпфы грунтовых насосов гидроциклонов 2-й стадии измельчения. В измельчительных комплексах, работающих по схеме сопряжения 2:1 $\left(\mathrm{KК}_{1}-\mathrm{ИК}_{3}, \mathrm{ИК}_{10}\right)$, установлены двенадцатидюймовые грунтовые насосы типа ГрАК $1600 / 50$, зарезервированные методом замещения восьмидюймовыми насосами типа ГрАК $350 / 40$, обеспечивающими работу ИК по схеме сопряжения 1:1 при отказе основного двенадцатидюймового насоса. В ИК, работающих по схеме сопряжения 1:1 (ИК $И_{6}$, ИК $\left._{7}\right)$, установлены восьмидюймовые грунтовые насосы, зарезервированные однотипными насосами методом замещения.

Цикл самоизмельчения руды включает 3 агрегата самоизмельчения $\left(\mathrm{AC}_{1}, \mathrm{AC}_{2}, \mathrm{AC}_{3}\right)$ типа $\mathrm{MMC} 70-73$, работающих по схеме сопряжения 1:1 соответственно с агрегатами $\mathrm{A}_{12}, \mathrm{~A}_{14}, \mathrm{~A}_{24}$ и односпиральными классификаторами $\varnothing 2000$ мм. Сливы классификаторов поступают в зумпфы двенадцатидюймовых грунтовых насосов, зарезервированных методом замещения однотипными насосами, откуда качаются в блоки гидроциклонов.

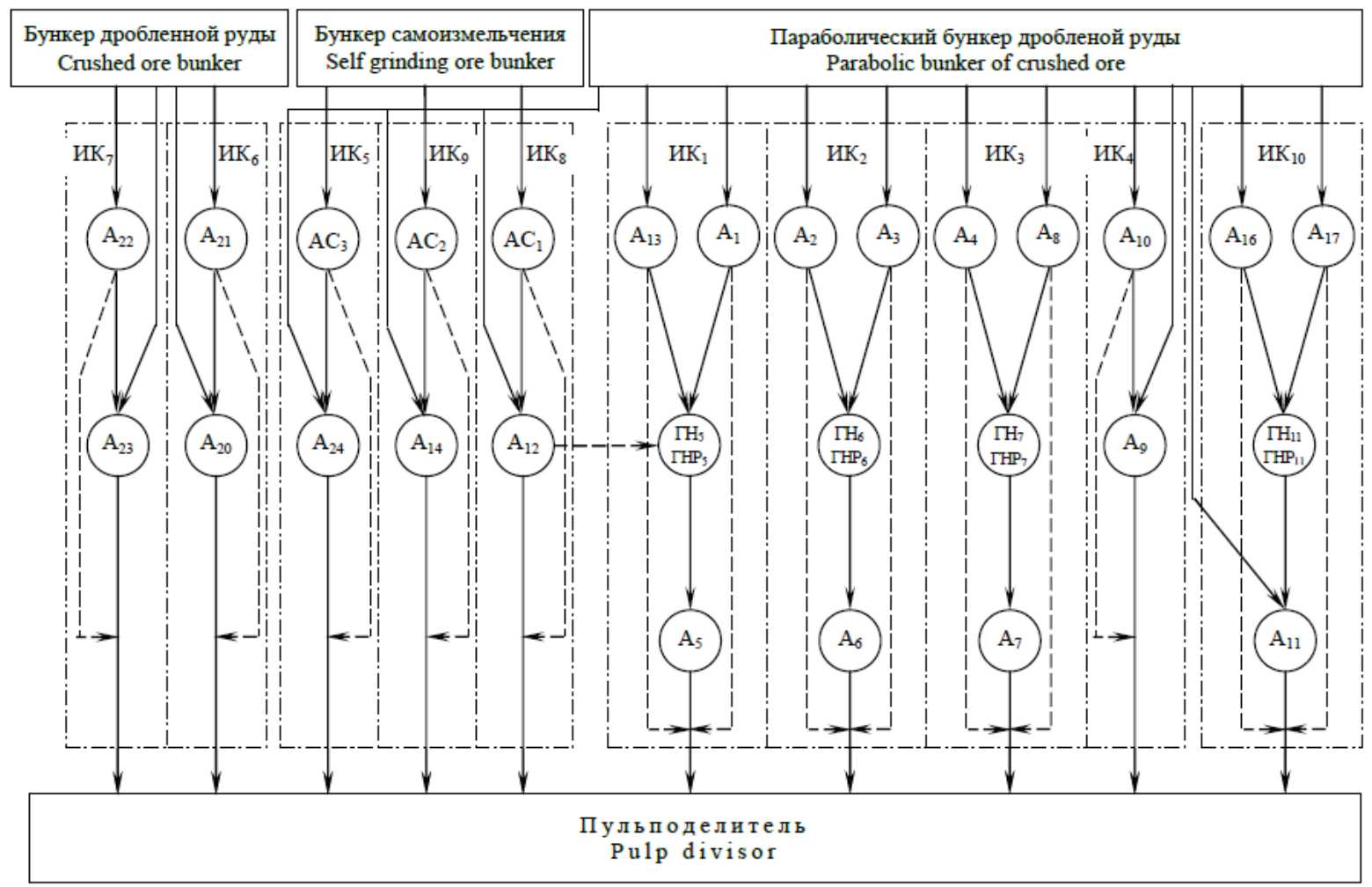

Pис. 1. Укрупненная структурная схема ТСИР

Fig. 1. Enlarged structural diagram of ore gridding technological system (OGTS) 


\section{Содержательное описание функционирования ТСИР} при отказах ее оборудования

В ТСИР, помимо основных связей между агрегатами, предусмотрены также резервные связи (на рис. 1 эти связи обозначены пунктиром), которые используются при отказах или принудительных простоях оборудования. Благодаря свойству перестроения (реконфигурации) структуры системы посредством использования резервных связей и способности измельчительных агрегатов функционировать в различных режимах, отказы оборудования не приводят к отказу системы в целом, а лишь снижают качество ее функционирования. Условия работоспособности ИА, ИК и возможные режимы их работы с использованием резервных связей определяются следующим образом.

ОИА и ИА 1-й стадии измельчения работоспособны, когда одновременно работоспособно входящее в их состав оборудование: мельницы, системы смазки и классификаторы.

Указанные агрегаты могут функционировать как самостоятельные ИА и как ИА 1-й стадии в составе ДИК при соотношении агрегатов 2:1 или 1:1. ИА 2-й стадии измельчения работоспособен лишь тогда, когда одновременно работоспособен хотя бы один из грунтовых насосов и входящие в ее состав компоненты (мельница, система смазки, классификатор). Измельчительные агрегаты 2-й стадии, которые одновременно подпитываются рудой $\left(\mathrm{A}_{11}, \mathrm{~A}_{9}, \mathrm{~A}_{20}, \mathrm{~A}_{23}, \mathrm{~A}_{14}, \mathrm{~A}_{24}\right)$, могут функционировать как самостоятельные одностадийные ИА при отказах измельчительных агрегатов 1-й стадии. Те ИА 2-й стадии, которые не подпитываются рудой $\left(\mathrm{A}_{7}, \mathrm{~A}_{6}, \mathrm{~A}_{5}\right)$ при одновременном отказе обоих ИА 1-й стадии, прекращают функционировать. Резервные и основные насосы, входящие в состав ИК $И_{5}, И_{6}, И_{7}, И_{8}, И_{9}, \mathrm{~A}_{13}$, однотипные, поэтому отказавший насос после восстановления переходит в резерв. Заметим, что резервные восьмидюймовые насосы, входящие в состав $И K_{2}, И_{3}, И_{5},{ }_{5} \kappa_{8}$, $И_{9}$, работают до момента окончания восстановления отказавшего основного насоса, который включается вместо резервного.

При необходимости ДИК $(2: 1)\left({ }_{1},{ }_{2}, \kappa_{3}, И_{10}\right)$ посредством реконфигурации структуры может функционировать как:

- самостоятельный ИА (1:0) и ДИК (1:1) - при отказе основного грунтового насоса, ДИК (1:1) при отказе основного грунтового насоса;

- ДИК (1:1) - при отказе одного из ИА 1-й стадии;

- два самостоятельных одностадийных ОИА (2:0) - при отказе ИА 2-й стадии или грунтовых насосов;

- ОИА (1:0) - при отказе обоих ИА 1-й стадии (только ИК ${ }_{10}$, который одновременно подпитывается рудой).

ДИК (2:1) полностью прекращает функционировать при одновременном отказе обоих ИА 1-й стадии и ИА 2-й стадии (или грунтовых насосов).
При отказах оборудования входящие в ДИК (1:1) $\left(\right.$ ИК $_{4}, И_{6}$, ИК $\left._{7}\right)$ указанные комплексы могут функционировать как ОИА (1:0) $\left(\mathrm{A}_{10}, \mathrm{~A}_{21}, \mathrm{~A}_{22}\right)$ при отказе ИА 2-й стадии (или $\left(\mathrm{A}_{9}, \mathrm{~A}_{20}, \mathrm{~A}_{23}\right)$ обоих грунтовых насосов), ОИА (1:0) $\left(\mathrm{A}_{9}, \mathrm{~A}_{10}, \mathrm{~A}_{23}\right)$ при отказе ИА 1-й стадии $\left(\mathrm{A}_{10}, \mathrm{~A}_{21}, \mathrm{~A}_{22}\right)$. ДИК $(1: 1)$ прекращает функционировать при одновременном отказе ИА 1-й и 2-й стадий (или обоих грунтовых насосов).

ДИК $(1: 1)\left({ }_{1},{ }_{5},{ }_{8}, И_{9}\right)$ при отказах оборудования могут функционировать как ОИА (1:0) при отказах ИА 1-й стадии $\left(\mathrm{MC}_{1}, \mathrm{MC}_{2}, \mathrm{MC}_{3}\right)$ или ИА 2-й стадии $\left(\mathrm{A}_{12}, \mathrm{~A}_{14}, \mathrm{~A}_{24}\right)$ или обоих грунтовых насосов. При ремонте классификаторов имеется возможность подачи разгрузки мельницы непосредственно в зумпф грунтовых насосов гидроциклонов 2-й стадии измельчения.

\section{Выбор наилучшей структуры резервных связей и рациональной стратегии перестроения структуры системы}

В результате детального рассмотрения различных вариантов введения структурной избыточности в ТСИР ЗММК и обсуждений с эксплуатирующими ее специалистами выяснилось, что кроме имеющихся в системе резервных связей можно ввести еще четыре дополнительные связи. Из всех технологически возможных вариантов структуры резервных связей, составленных с учетом наложенного ограничения, путем исключения заведомо явно малоэффективных вариантов были выбраны четыре конкурирующих варианта (табл. 1).

Для выбранных вариантов структуры резервных связей были рассмотрены две конкурирующие стратегии («A» и «B») использования резервных связей. Стратегия «А» отличается от стратегии «В» тем, что:

a) при отказе агрегата $\mathrm{A}_{9}$ связь $\mathrm{A}_{10} \rightarrow \mathrm{A}_{11}$ используется независимо от состояний агрегатов $\mathrm{A}_{16}$ и $\mathrm{A}_{17}$ (при стратегии $\mathrm{B}$ связь $\mathrm{A}_{10} \rightarrow \mathrm{A}_{11}$ используется только при отказе одного из указанных агрегатов);

б) при отказе агрегата $\mathrm{A}_{9}$ связь $\mathrm{A}_{10} \rightarrow \mathrm{A}_{7}$ используется независимо от состояний агрегатов $\mathrm{A}_{8}$ и $\mathrm{A}_{4}$ (при стратегии В указанная связь используется только при отказе агрегатов $\mathrm{A}_{8}$ и $\mathrm{A}_{4}$ );

в) при отказе агрегата $\mathrm{A}_{10}$ связь $\mathrm{A}_{16} \rightarrow \mathrm{A}_{9}$ используется независимо от состояния агрегата $\mathrm{A}_{11}$ (при стратегии В указанная связь используется только при отказе агрегата $\mathrm{A}_{11}$ );

г) при отказе агрегата $\mathrm{A}_{9}$ связь $\mathrm{A}_{10} \rightarrow \mathrm{A}_{7}$ используется при наличии связи $\mathrm{A}_{4} \rightarrow \mathrm{A}_{6}$ (при стратегии $\mathrm{B}$ связь $\mathrm{A}_{10} \rightarrow \mathrm{A}_{7}$ используется независимо от применения указанной связи).

Для каждого из восьми конкурирующих вариантов была построена математическая модель процесса принятия решений по реконфигурации структуры ТСИР в виде дерева решений [10-13]. Дерево решений - это способ представления правил в иерархической, последовательной структуре, где каждому объекту (входному сигналу, опи- 
таблица 1. Результаты илитационных экспериментов

Table 1. Results of simulation experiments

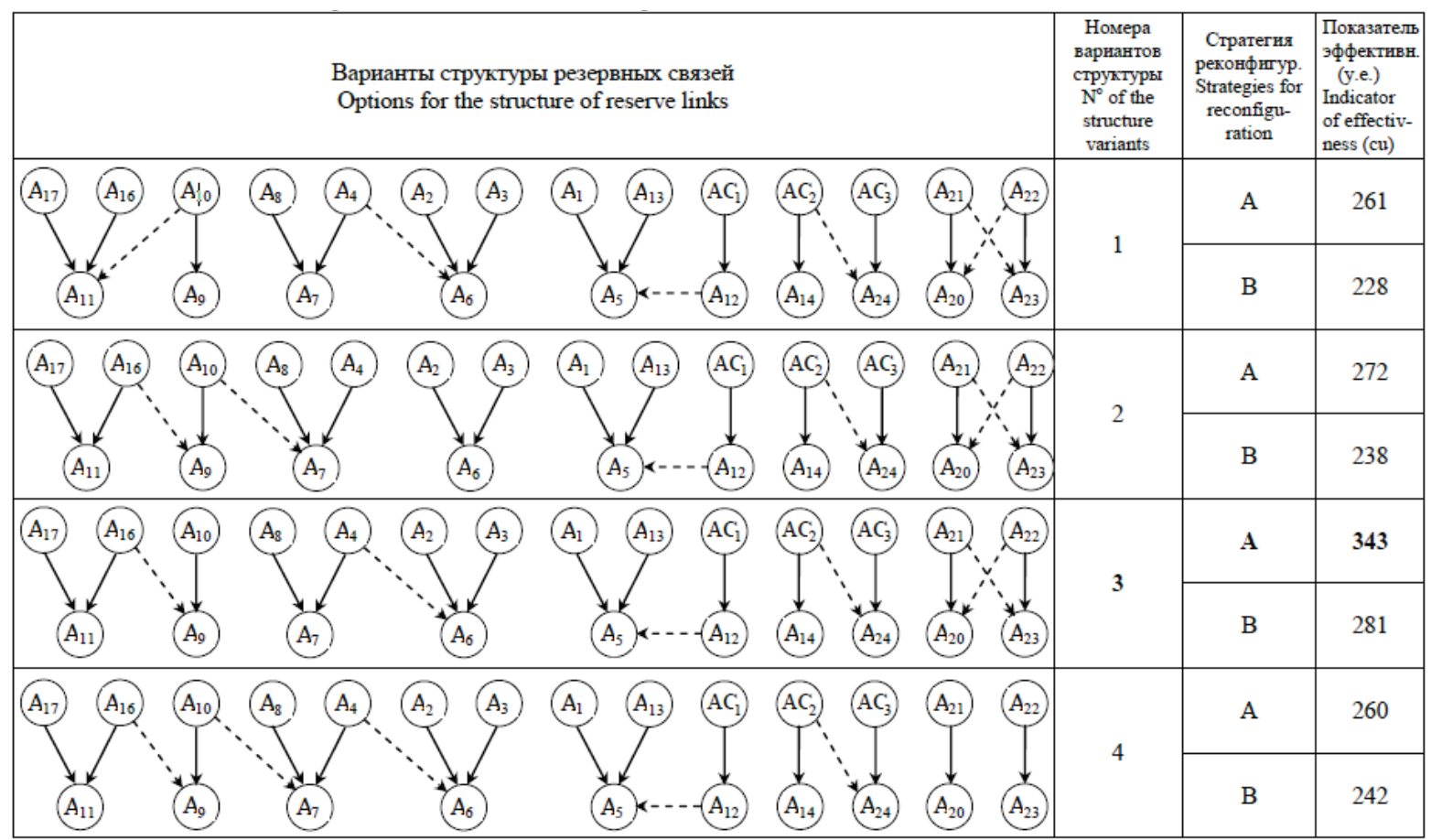

сывающему состояние системы) соответствует единственный узел, дающий решение.

Метод дерева решений, который принадлежит методам мягких вычислений (методы искусственного интеллекта, нейронных сетей, генетические методы и т. п. $[14,15])$, является одним из классических методов интеллектуального анализа данных (data mining), получивший в последнее время практическое применение в области моделирования и оптимизации процессов обогащения полезных ископаемых [16-20].

Решение задачи выбора наилучшей структуры резервных связей между измельчительными агрегатами и рациональной стратегии реконфигурации структуры ТСИР при отказах ее агрегатов осуществлено методом компьютерного моделирования. Компьютерная модель, ориентированная на решение поставленной задачи, представляет собой композицию из трех моделей (рис. 2). Первая из них воспроизводит процесс возникновения отказов и восстановления измельчительного оборудования - 21 шаровых мельниц и 3 мельниц самоизмельчения, 24 систем смазки мельниц, 18 классификаторов, 20 грунтовых насосов (элементов модели $\left.E_{i}^{0}, i=\overline{1,86}\right)$, вторая модель имитирует процесс функционирования ТСИР под воздействием процесса возникновения отказов и восстановления ее оборудования, а третья модель формирует значение показателя эффективности для каждой реализации процесса функционирования системы в восьмичасовом интервале времени. Построение первой модели осуществлено с использованием функций распределения времени работы между соседними отказами и времени восстановления отказавшего оборудования, идентифицированных на основании статистических данных о надежности измельчительного оборудования [8]. Ниже приведены аналитические выражения для плотностей распределения времени работы между отказами $g_{i}\left(\tau_{\mathrm{p}}\right)$ и времени восстановления $f_{i}\left(\tau_{\mathrm{B}}\right)$ измельчительного оборудования:

1) Мельница 1-й стадии типа МШР $3200 \times 3800$

$$
\begin{aligned}
& g_{i}\left(\tau_{\mathrm{p}}\right)=\hat{\lambda} \exp \left(-\hat{\lambda} \hat{o}_{\mathrm{p}}\right)=1,925 \cdot 10^{-2} \exp \left(-1,925 \cdot 10^{-2} \tau_{\mathrm{p}}\right) ; \\
& f_{i}\left(\tau_{\mathrm{B}}\right)=\frac{k \tau_{\mathrm{B}}^{k-1}}{\widehat{\alpha}} \cdot \exp \left(-\frac{\tau_{\mathrm{B}}^{k}}{\widehat{\alpha}}\right)=0,469 \tau_{\mathrm{B}}^{-0,3} \exp \left(-0,67 \tau_{\mathrm{B}}^{0,7}\right) .
\end{aligned}
$$

2) Мельница 2-й стадии типа МШР $3200 \times 3800$

$$
\begin{aligned}
& g_{i}\left(\tau_{\mathrm{p}}\right)=\hat{\lambda} \exp \left(-\hat{\lambda} \hat{o}_{\mathrm{p}}\right)=2,05 \cdot 10^{-2} \exp \left(-2,05 \cdot 10^{-2} \tau_{\mathrm{p}}\right) ; \\
& f_{i}\left(\tau_{\mathrm{B}}\right)=\frac{k \tau_{\mathrm{B}}^{k-1}}{\widehat{\alpha}} \exp \left(-\frac{\tau_{\mathrm{B}}^{k}}{\widehat{\alpha}}\right)=0,48 \tau_{\mathrm{B}}^{-0,4} \exp \left(-0,798 \tau_{\mathrm{B}}^{0,6}\right) .
\end{aligned}
$$

3) Мельница 2-й стадии типа МШР $3200 \times 3100$

$$
\begin{aligned}
& g_{i}\left(\tau_{\mathrm{p}}\right)=\hat{\lambda} \exp \left(-\hat{\lambda} \hat{o}_{\mathrm{p}}\right)=2,05 \cdot 10^{-2} \exp \left(-2,05 \cdot 10^{-2} \tau_{\mathrm{p}}\right) ; \\
& f_{i}\left(\tau_{\mathrm{B}}\right)=\frac{k \tau_{\mathrm{B}}^{k-1}}{\widehat{\alpha}} \exp \left(-\frac{\tau_{\mathrm{B}}^{k}}{\widehat{\alpha}}\right)=0,48 \tau_{\mathrm{B}}^{-0,4} \exp \left(-0,798 \tau_{\mathrm{B}}^{0,6}\right) .
\end{aligned}
$$

4) Мельница 1-й стадии типа МШР $3200 \times 3100$

$$
\begin{aligned}
f_{i}\left(\tau_{\mathrm{B}}\right) & =\hat{\lambda} \exp \left(-\hat{\lambda} \hat{o}_{\mathrm{p}}\right)=1,785 \cdot 10^{-2} \exp \left(-1,785 \cdot 10^{-2} \tau_{\mathrm{p}}\right) ; \\
f_{i}\left(\tau_{\mathrm{B}}\right) & =\frac{k \tau_{\mathrm{B}}^{k-1}}{\widehat{\alpha}} \exp \left(-\frac{\tau_{\mathrm{B}}^{k}}{\widehat{\alpha}}\right)=0,492 \tau_{\mathrm{B}}^{-0,4} \exp \left(-0,82 \tau_{\mathrm{B}}^{0,6}\right) .
\end{aligned}
$$

5) Классификатор типа 2 КСН-2,4

$$
\begin{gathered}
g_{i}\left(\tau_{\mathrm{p}}\right)=\hat{\lambda} \exp \left(-\hat{\lambda} \hat{o}_{p}\right)=4,4 \cdot 10^{-3} \exp \left(-4,4 \cdot 10^{-3} \tau_{p}\right) ; \\
f_{i}\left(\tau_{\mathrm{B}}\right)=\frac{\exp \left[-\left(\lg \tau_{\mathrm{B}}-\widehat{\mu}^{2} / 2 \hat{\sigma}^{2}\right]\right.}{\hat{\sigma} \sqrt{2 \pi} \tau_{\mathrm{B}}}=\frac{\exp \left[-\left(\lg \tau_{\mathrm{B}}-0,14\right)^{2} / 0,46\right]}{0,48 \sqrt{2 \pi} \tau_{\mathrm{B}}} .
\end{gathered}
$$




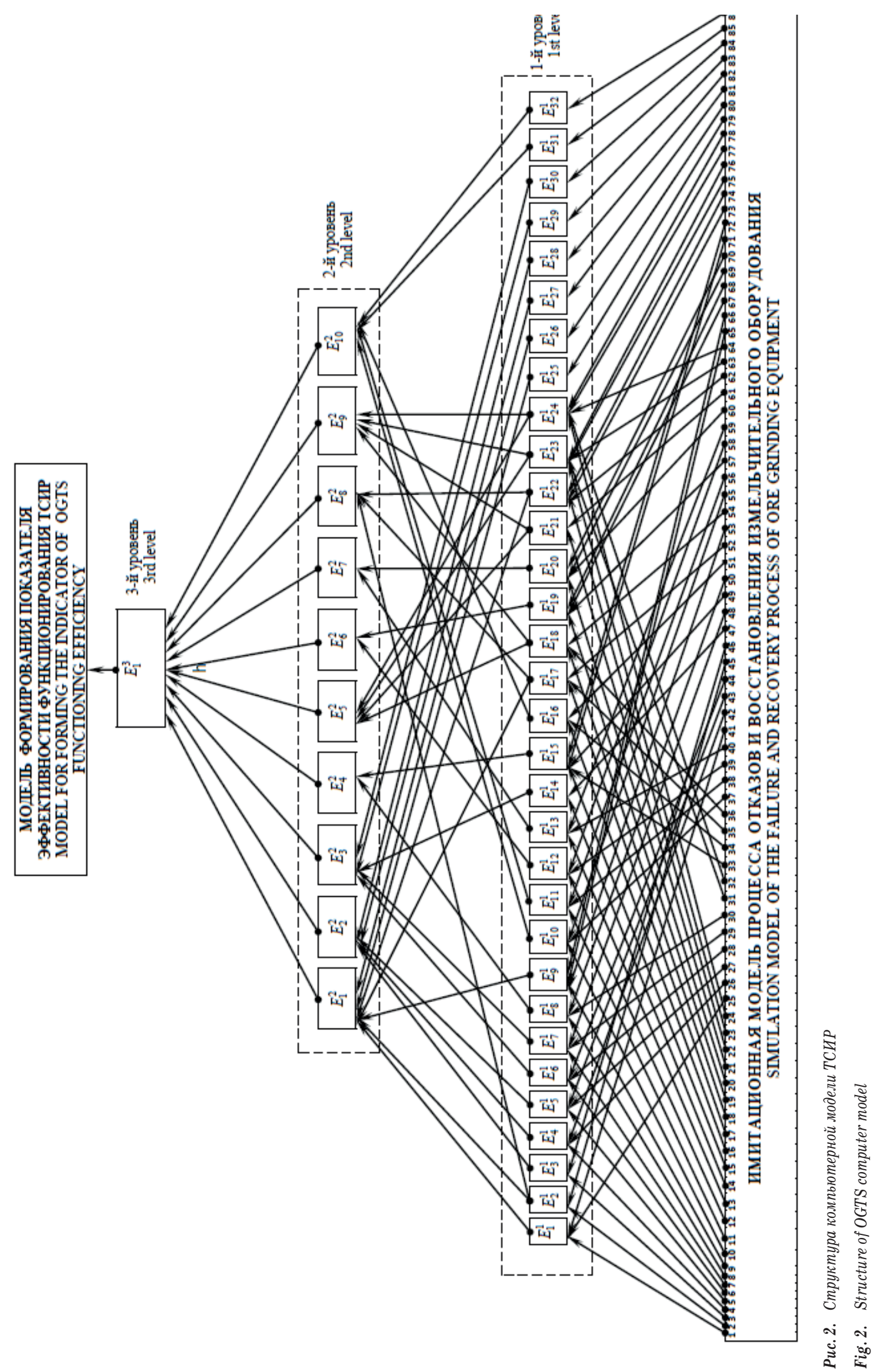


6) Система смазки мельниц

$$
\begin{gathered}
g_{i}\left(\tau_{\mathrm{p}}\right)=\hat{\lambda} \exp \left(-\hat{\lambda} \hat{o}_{\mathrm{p}}\right)=2,6 \cdot 10^{-3} \exp \left(-2,6 \cdot 10^{-3} \tau_{\mathrm{p}}\right) ; \\
f_{i}\left(\tau_{\mathrm{B}}\right)=\frac{\exp \left[-\left(\lg \tau_{\mathrm{B}}-\widehat{\mu}\right)^{2} / 2 \hat{\sigma}^{2}\right]}{\widehat{\sigma} \sqrt{2 \pi} \tau_{\mathrm{B}}}= \\
=\frac{\exp \left[-\left(\lg \tau_{\mathrm{B}}-0,12\right)^{2} / 0,52\right]}{0,52 \sqrt{2 \pi} \tau_{\mathrm{B}}}
\end{gathered}
$$

7) Грунтовой насос типа ГрАК $350 / 40$

$$
\begin{gathered}
g_{i}\left(\tau_{\mathrm{p}}\right)=\frac{\tau_{\mathrm{p}}}{\hat{\sigma}^{2}} \exp \left(-\frac{\tau_{\mathrm{p}}^{2}}{2 \hat{\sigma}^{2}}\right)=\frac{\tau_{\mathrm{p}}}{4225} \exp \left(-\frac{\tau_{\mathrm{p}}^{2}}{8450}\right) ; \\
f_{i}\left(\tau_{\mathrm{B}}\right)=\frac{\exp \left[-\left(\lg \tau_{\mathrm{B}}-\widehat{\mu}\right)^{2} / 2 \widehat{\sigma}^{2}\right]}{\widehat{\sigma} \sqrt{2 \pi} \tau_{\mathrm{B}}}= \\
=\frac{\exp \left[-\left(\lg \tau_{\mathrm{B}}-0,292\right)^{2} / 0,174\right]}{0,295 \sqrt{2 \pi} \tau_{\mathrm{B}}} .
\end{gathered}
$$

8) Грунтовой насос типа ГрАК $1600 / 50$

$$
\begin{gathered}
g_{i}\left(\tau_{\mathrm{p}}\right)=\frac{\tau_{\mathrm{p}}}{\hat{\sigma}^{2}} \exp \left(-\frac{\tau_{\mathrm{p}}^{2}}{2 \widehat{\sigma}}\right)=\frac{\tau_{\mathrm{p}}}{3150} \exp \left(-\frac{\tau_{\mathrm{p}}^{2}}{6300}\right) ; \\
f_{i}\left(\tau_{\mathrm{B}}\right)=\frac{\exp \left[-\left(\lg \tau_{\mathrm{B}}-\widehat{\mu}\right)^{2} / 2 \hat{\sigma}^{2}\right]}{\widehat{\sigma} \sqrt{2 \pi} \tau_{\mathrm{B}}}= \\
=\frac{\exp \left[-\left(\lg \tau_{\mathrm{B}}-0,4555\right)^{2} / 0,196\right]}{0,313 \sqrt{2 \pi} \tau_{\mathrm{B}}} .
\end{gathered}
$$

9) Мельница самоизмельчения типа МMC-70-23

$$
\begin{gathered}
g_{i}\left(\tau_{\mathrm{p}}\right)=1,81 \cdot 10^{-2} \exp \left(-1,81 \cdot 10^{-2} \tau_{\mathrm{p}}\right) ; \\
f_{i}\left(\tau_{\mathrm{B}}\right)=0,44 \tau_{\mathrm{B}}^{-0,3} \exp \left(-0,63 \tau_{\mathrm{B}}^{0,7}\right) .
\end{gathered}
$$

10)Односпиральный классификатор типа КСН- 2,0

$$
\begin{aligned}
g_{i}\left(\tau_{\mathrm{p}}\right) & =5,2 \cdot 10^{-3} \exp \left(-5,2 \cdot 10^{-3} \tau_{\mathrm{p}}\right) ; \\
f_{i}\left(\tau_{\mathrm{B}}\right) & =\frac{\exp \left[-\left(\lg \tau_{\mathrm{B}}-0,18\right)^{2} / 0,5\right]}{0,52 \sqrt{2 \pi} \tau_{\mathrm{B}}} .
\end{aligned}
$$

Выходной сигнал имитационной модели процесса отказов и восстановления оборудования ТСИР $y^{0}(t)=\left(y_{1}^{0}(t), y_{2}^{0}(t), \ldots, y_{86}^{0}(t)\right)$ представляет собой случайный вектор, компоненты которого в зависимости от состояния элементов $E_{i}^{0}, i=1,86$ (работоспособное или отказ) могут принимать значения «1» или «0».

Одной из основных проблем, препятствующих построению имитационной модели функционирования ТСИР, является преодоление ее большой размерности (числа состояний). Так, при построении модели системы, состоящей из 20 бинарных элементов, число рассматриваемых состояний превышает $10^{6}$. Одним из возможных путей решения описанной проблемы является применение концепции иерархического многоуровневого (стратифицированного) описания систем $[6,7]$. Ее сущность заключается в том, что процесс функционирования системы описывается не одной моделью большой размерности, а иерархией сравнительно простых моделей, каждая из которых описывает процесс функционирования исследуемой системы на определенном уровне абстрагирования (детализации).

В настоящей работе в основе имитационной модели функционирования ТСИР использована разработанная нами обобщенная стратифицированная модель [6, 7], позволяющая успешно преодолеть сложность формализации ТСИР.

Учитывая характер поставленной задачи, удобство описания, а также конструктивные и функциональные особенности ТСИР, ее функционирование описано на трех следующих стратах (уровнях описания): страте измельчительных агрегатов (ИА), страте измельчительных комплексов (ИК) и системной страте.

\section{Страта измельчительных агрегатов}

На данной страте ТСИР представлена совокупностью 32 ИА - подсистем первого уровня $E_{i}{ }^{1}$, $i=\overline{1,32}$, полученных в результате декомпозиции системы, состоящей из элементов $E_{i}^{0}, i=\overline{1,86}$.

Каждая подсистема первого уровня $E_{i}{ }^{1}$ рассмотрена как объект с двумя возможными состояниями и формализована в виде временной статической системы без памяти $S_{i}{ }^{1}[6,7]$, описываемой множествами $X_{i}^{1}$ (входных сигналов $\left.x_{i}^{1}(t)\right), Y_{i}^{1}$ (выходных сигналов $\left.y_{i}^{1}(t)\right), T_{i}^{1}$ (моментов времени $t$ ) и оператором $H_{i}{ }^{1}$. Множество $X_{i}{ }^{1}$ каждой подсистемы $E_{i}{ }^{1}$ определяется как декартово произведение множеств $\{0 ; 1\}$ выходных сигналов входящих в ее состав элементов $E_{i}^{0}$ и элементов других подсистем, влияющих на работоспособности подсистемы $E_{i}{ }^{1}$. Множество $Y_{i}^{1}$ включают два элемента (0 - состояние отказа, 1 - работоспособное состояние). Оператор $H_{i}{ }^{1}$ представляет собой логическую функцию работоспособности подсистемы $E_{i}^{1}$, описывающую условие работоспособности данной подсистемы в зависимости от работоспособности входящих в ее состав и влияющих на нее элементов.

Ниже приведены аналитические выражения операторов $H_{i}{ }^{1}, i=\overline{1,8}$ ( $t$ упущено) для первых 8 подсистем $E_{i}{ }^{1}$ :

$$
\begin{gathered}
y_{1}^{1}=H_{1}^{1}\left(x_{1}^{1}\right)=x_{1,1}^{1} \wedge x_{2,1}^{1} \wedge x_{3,1}^{1}=y_{1}^{0} \wedge y_{25}^{0} \wedge y_{41}^{0} ; \\
y_{2}^{1}=H_{2}^{1}\left(x_{2}^{1}\right)=x_{2,1}^{1} \wedge x_{2,2}^{1}=y_{2}^{0} \wedge y_{45}^{0} ; \\
y_{3}^{1}=H_{3}^{1}\left(x_{3}^{1}\right)=x_{3,1}^{1} \wedge x_{3,2}^{1}=y_{3}^{0} \wedge y_{46}^{0} ; \\
y_{4}^{1}=H_{4}^{1}\left(x_{4}^{1}\right)=x_{4,1}^{1} \wedge x_{4,2}^{1} \wedge x_{4,3}^{1}=y_{4}^{0} \wedge y_{26}^{0} \wedge y_{42}^{0} ; \\
y_{5}^{1}=H_{5}^{1}\left(x_{5}^{1}\right)=x_{5,1}^{1} \wedge x_{5,2}^{1} \wedge x_{5,3}^{1}=y_{5}^{0} \wedge y_{27}^{0} \wedge y_{43}^{0} ; \\
y_{6}^{1}=H_{6}^{1}\left(x_{6}^{1}\right)=x_{6,1}^{1} \wedge x_{6,2}^{1} \wedge x_{6,3}^{1}=y_{6}^{0} \wedge y_{28}^{0} \wedge y_{44}^{0} ; \\
y_{7}^{1}=H_{7}^{1}\left(x_{7}^{1}\right)=x_{7,1}^{1} \wedge x_{7,2}^{1} \wedge x_{7,3}^{1}=y_{7}^{0} \wedge y_{29}^{0} \wedge y_{48}^{0} ; \\
y_{8}^{1}=H_{8}^{1}\left(x_{8}^{1}\right)=x_{8,1}^{1} \wedge x_{8,2}^{1} \wedge x_{8,3}^{1}=y_{8}^{0} \wedge y_{30}^{0} \wedge y_{50}^{0} .
\end{gathered}
$$

\section{Страта измельчительных комплексов}

На этой страте ТСИР представлена в виде совокупности 10 измельчительных комплексов - подсистем второго уровня $E_{i}^{2}, i=\overline{1,10}$. Каждый ИК, в 
зависимости от работоспособности входящих в его состав или влияющих на его работу ИА, может работать в одном из технологически возможных режимов по определенной схеме измельчения. Каждый режим работы ИК $E_{i}^{2}$ характеризуется конкретным набором значений его выходных характеристик $y_{i}^{2}=\left(y_{i, 1}^{2}, y_{i, 2}^{2}, y_{i, 3}^{2}\right)$, где $y_{i, 1}^{2}-$ производительность комплекса; $y_{i, 2}^{2}$ - процентное содержание класса $\leq 80$ мкм в измельченном продукте (пульпе); $y_{i, 3}^{2}$ - плотность выходной пульпы.

Обозначим через $x_{i}^{2}(t)=\left(x_{i, 1}^{2}(t), x_{i, 2}^{2}(t), \ldots, x_{i, n_{i}}^{2}(t)\right)$ совокупность выходных характеристик состояний в момент $t$ тех ИА, от работоспособности которых зависит выбор структуры и режима работы ИК $E_{i}^{2}$. В каждый момент $t \in T^{1}$, когда происходит изменение работоспособности ИА, в соответствии со значением вектора $x_{i}^{2}(t)$ происходит перестроение структуры комплекса $E_{i}{ }^{2}$ и переход в новый режим работы, характеризуемый новым значением вектоpa $y_{i}^{2}(t)$.

Каждый ИК $E_{i}^{2}$, формализованный в виде временной статической системы без памяти $S_{i}{ }^{2}$, характеризуется четверкой $\left\langle T_{i}^{2}, X_{i}^{2}, Y_{i}{ }^{2}, H_{i}{ }^{2}\right\rangle$. Каждое множество $T_{i}^{2}, i=\overline{1,10}$ совпадает с множеством $T^{1}=T^{0}$ (множество моментов изменения состояний элементов) $E_{i}{ }^{0}, i=\overline{1,86}$. Входной сигнал $x_{i}^{2}(t)$ каждой $S_{i}{ }^{2}$ представляет собой упорядоченную совокупность выходных сигналов соответствующих подсистем первого уровня. В качестве выходного сигнала любого элемента $S_{i}^{2}$ рассматривается вектор выходных характеристик $y_{i}^{2}(t)=\left(y^{2}{ }_{i, 1}(t), y_{i, 2}^{2}(t), y_{i, 3}^{2}(t)\right)$ соответствующей подсистемы (ИК) $E_{i}^{2}$. Множество $Y_{i}^{2}$ элемента $S_{i}^{2}$ представляет собой совокупность значений вектора выходных характеристик подсистемы $E_{i}{ }^{2}$, соответствующих всевозможным режимам ее работы. Каждый оператор $H_{i}^{2}$, реализую- щий отображение $X_{i}^{2} \rightarrow Y_{i}^{2}$, представляет собой бинарную поисковую признаковую структуру - алгоритм, который по заданному входному сигналу $x_{i}^{2}(t) \in X_{i}^{2}$, описывающему работоспособность входящих в состав подсистемы $E_{i}^{2}$ и влияющих на ее функционирование подсистем первого уровня, осуществляет поиск и выдачу соответствующего выходного сигнал $y_{i}^{2}(t) \in Y_{i}^{2}$. На рис. 3 приведена структура одного из десяти операторов $H_{i}^{2}$.

Среднестатистические значения выходных характеристик $y_{i}^{2}(t)=\left(y_{i, 1}^{2}(t), y_{i, 2}^{2}(t), y_{i, 3}^{2}(t)\right)$ измельчительных комплексов для всевозможных режимов работы подсистемы $E_{5}^{2}$ приведены в табл. 2.

Таблица 2. Схемы измельчения и режимы работы подсистемы $E_{5}^{2}\left(И K_{5}\right)$

Table 2. Schemes and grinding modes of subsystem $E_{5}^{2}\left(G C_{5}\right)$

\begin{tabular}{|c|c|c|c|c|c|}
\hline \multirow[b]{2}{*}{ 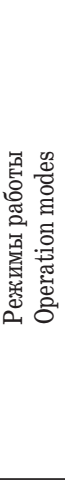 } & \multicolumn{2}{|c|}{$\begin{array}{l}\text { Схемы измельчения } \\
\text { Schemes of grinding }\end{array}$} & \multicolumn{3}{|c|}{$\begin{array}{c}\text { Среднестатистические значе- } \\
\text { ния выход. характеристик } \\
\text { Average values of output } \\
\text { characteristics }\end{array}$} \\
\hline & $\begin{array}{c}\text { Схема } \\
\text { имельчения } \\
\text { Scheme of } \\
\text { grinding }\end{array}$ & $\begin{array}{l}\text { Сопряжение } \\
\text { мельниц } \\
\text { Conjugation } \\
\text { of mills }\end{array}$ & 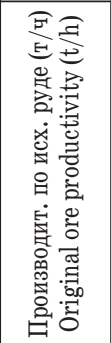 & 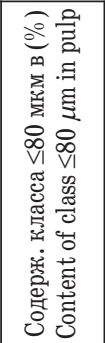 & 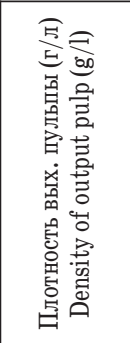 \\
\hline$v$ & $\begin{array}{c}\text { 2-стадийный } \\
\text { 2-stage }\end{array}$ & $\begin{array}{c}(1: 1), \\
A_{24} \rightarrow A C_{3}\end{array}$ & $q_{1}^{v}=126,7$ & $q_{2}{ }^{v}=56,3$ & $q_{3}{ }^{v}=1344,7$ \\
\hline$w$ & $\begin{array}{c}\text { 1-стадийный } \\
\text { 1-stage }\end{array}$ & $\begin{array}{c}(1: 0) \\
A C_{3}\end{array}$ & $q_{1}^{\omega}=80$ & $q_{2}{ }^{w}=56,3$ & $q_{3}{ }^{w}=1273,3$ \\
\hline$\beta$ & $\begin{array}{c}\text { 2-стадийный } \\
\text { 2-stage }\end{array}$ & $\begin{array}{c}(2: 1), \\
A_{14} \rightarrow A C_{3} \rightarrow A_{24}\end{array}$ & $q_{1}^{\beta}=130$ & $q_{2}^{\beta}=56,3$ & $q_{3}^{\beta}=1344$ \\
\hline
\end{tabular}

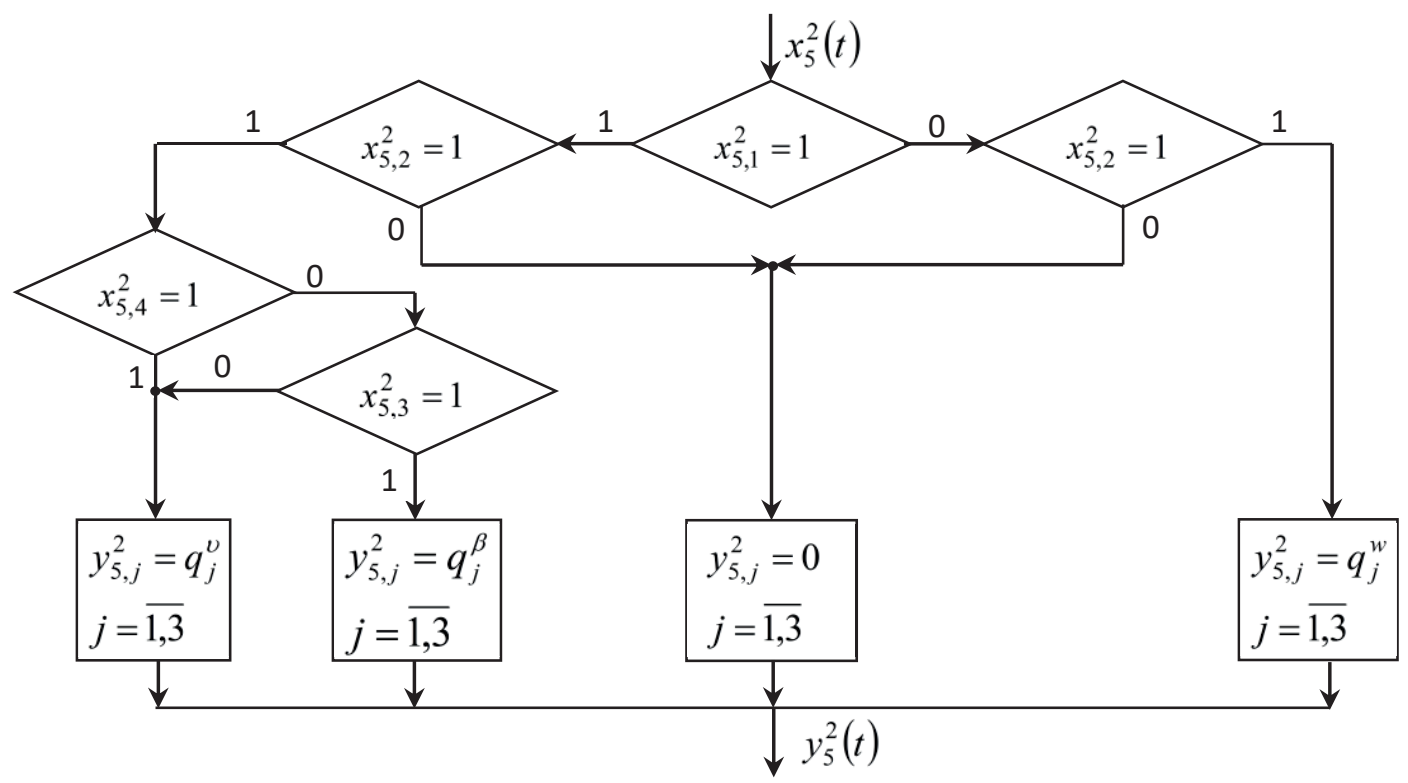

Puc. 3. Cтруктура оператора $H_{5}^{2}$

Fig. 3. Structure of the operator $\mathrm{H}_{5}^{2}$ 


\section{Системная страта}

На данной страте ТСИР рассматривается как одна крупная подсистема $E_{1}^{3}$ третьего уровня, представляющая собой смеситель (пульподелитель), входом которого является совокупность выходных продуктов всех измельчительных комплексов, а выходом - объединенная выходная пульпа, поступающая на флотацию.

Обозначим через $y_{1,1}^{3}(t), y_{1,2}^{3}(t), y_{1,3}^{3}(t)$ значения выходных характеристик подсистемы $E_{1}^{3}$ в момент времени $t$ : ее производительность, процентное содержание класса $\leq 80$ мкм и плотность объединенной пульпы. Соответствующие характеристики входных потоков, представляющие собой выходные характеристики ИК, обозначим через $x_{i, 1}^{3}(t)=y_{i, 1}^{2}(t), x_{i, 2}^{3}(t)=y_{i, 2}^{2}(t), x_{i, 3}^{3}(t)=y_{i, 3}^{2}(t), i=\overline{1,10}$.

Нами показано [7], что общая производительность ТСИР $y_{1,1}^{3}(t)$, процент содержания класса $\leq 80$ мкм $y_{1,2}^{3}(t)$ в объединенной пульпе и ее плотность $y_{1,3}^{3}(t)$ связаны с характеристиками отдельных комплексов следующими соотношениями:

$$
\begin{aligned}
y_{1,1}^{3}(t)= & H_{1,1}^{3}\left(x_{1,1}^{3}(t), x_{1,2}^{3}(t), \ldots, x_{1,10}^{3}(t)\right)=\sum_{i=1}^{10} x_{1, i}^{3}(t), \\
& y_{1,2}^{3}(t)=H_{1,2}^{3}\left(x_{1,1}^{3}(t), \ldots, x_{1,20}^{3}(t)\right)= \\
= & {\left[\sum_{i=1}^{10} x_{1, i}^{3}(t) \cdot x_{1,(i+10)}^{3}(t)\right] / \sum_{i=1}^{10} x_{1, i}^{3}(t), }
\end{aligned}
$$

$$
\begin{gathered}
y_{1,3}^{3}(t)= \\
=H_{1,3}^{3}\left(x_{1,1}^{3}(t), x_{1,2}^{3}(t), \ldots, x_{1,10}^{3}(t), x_{1,20}^{3}(t), \ldots, X_{1,30}^{3}(t)\right)= \\
=\left[\sum_{i=1}^{10} \frac{x_{1, i}^{3}(t) x_{1,(i+20)}^{3}(t)}{x_{1,(i+20)}^{3}(t)-1000}\right] / \sum_{i=1}^{10} \frac{x_{1, i}^{3}(t)}{x_{1,(i+20)}^{3}(t)-1000} .
\end{gathered}
$$

Модель формирования значений показателя эффективности функционирования ТСИР включает алгоритмическую модель формирования ее выходных среднесменных показателей для реализованных траекторий функционирования системы и регрессионную модель, описывающую статистическую зависимость прибыли, получаемой от производства медно-молибденовых концентратов в восьмичасовом интервале времени, от выходных среднесменных показателей ТСИР.

При решении поставленной задачи в качестве сравнительной оценки эффективности каждого варианта структуры резервных связей между ИА была выбрана величина прироста прибыли (в у.е.), получаемой от производства медно-молибденовых концентратов в восьмичасовом интервале времени при использовании данного варианта. Как видно из табл. 1 , в результате имитационных экспериментов с компьютерной модели ТСИР в качестве наилучшей структуры резервных связей был выбран третий вариант с рациональной стратегией «A» реконфигурации структуры.

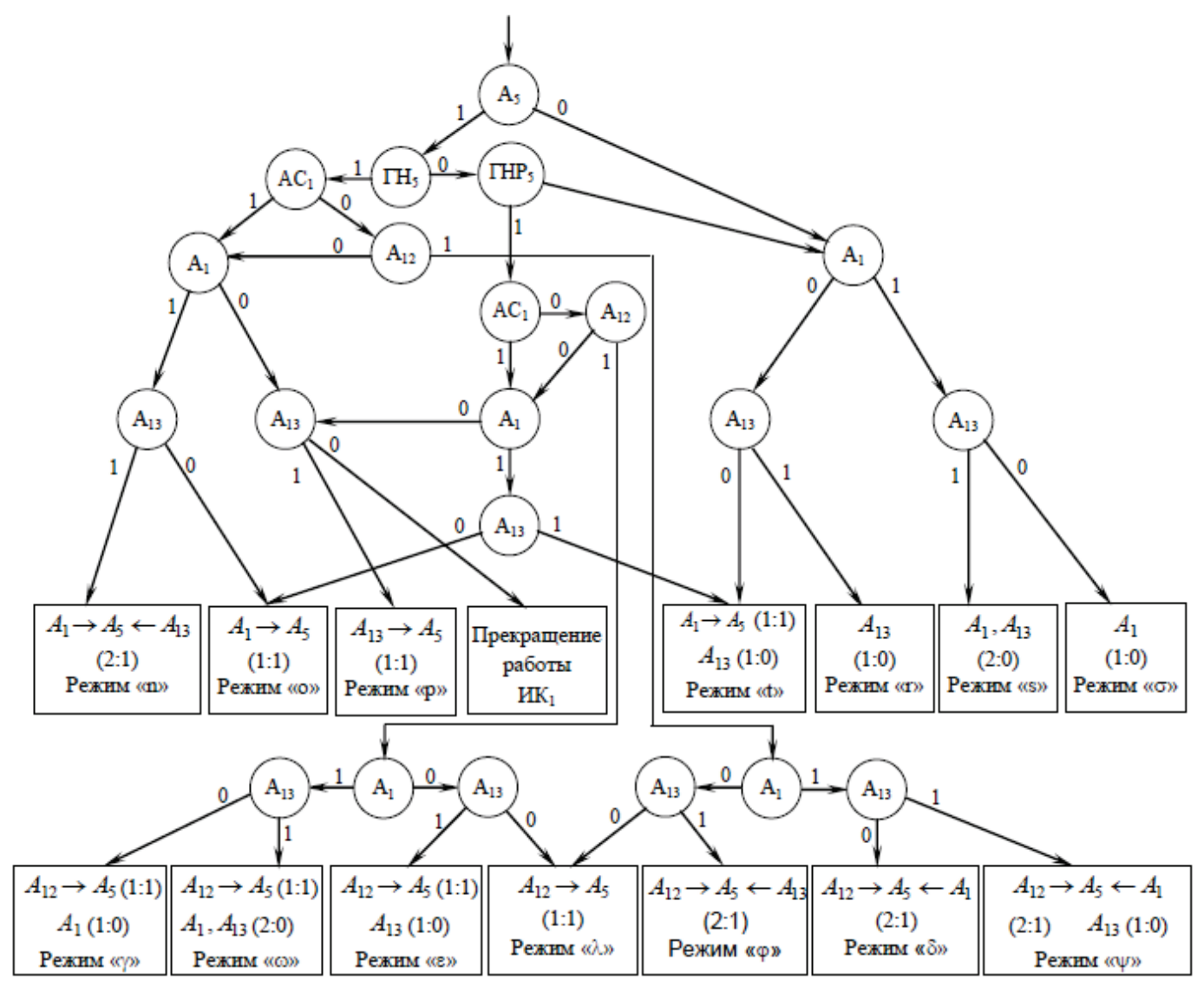

Pис. 4. Дерево решений для ИК

Fig. 4. Decision tree for gridding complex $\left(G C_{1}\right)$ 


\section{Компьютерная модель принятия решений} по реконфигурации структуры ТСИР

Оператору измельчительного отделения нелегко запомнить сложную процедуру выбора наилучшей структуры системы в зависимости от работоспособности измельчительных агрегатов и своевременно принять наиболее рациональные для конкретно сложившихся отказовых ситуаций решения. В этой связи возникает необходимость автоматизации процесса принятия решений по реконфигурации структуры ТСИР при отказах ее оборудования.

В соответствии с выбранной наилучшей структурой резервных связей и рациональной стратегией реконфигурации структуры ТСИР разработана математическая модель процесса принятия решений по реконфигурации структуры ТСИР при отказах ее агрегатов в виде дерева решений (рис. 3). Данная модель состоит из 10 последовательно соединенных деревьев решений, каждое из которых представляет процесс принятия решений по реконфигурации структуры соответствующего измельчительного комплекса (на рис. 4 приведено дерево решений для ИК ${ }_{1}$ ).

На основании построенных деревьев решений для наилучшего варианта разработана компьютер- ная модель принятия решений по реконфигурации структуры (КМПРРС) ТСИР при отказах ее агрегатов. КМПРРС состоит из 10 модулей, каждый из которых при отказах измельчительных агрегатов ТСИР позволяет принять наилучшее решение по реконфигурации структуры и выбору режимов работы соответствующего измельчительного комплекса. Блок-схема одного из модулей (для измельчительного комплекса $И_{1}$ ) приведена на рис. 5.

Входной сигнал КМПРРС представляет собой 32 мерный бинарный вектор $\hat{z}(t)=\left(\hat{z}_{1}(t), \hat{z}_{2}(t), \ldots, \hat{z}_{32}(t)\right)$, описывающий состояние ТСИР в момент времени $t$. Каждая компонента вектора $\hat{z}(t)$ в зависимости от состояния соответствующего измельчительного агрегата (или грунтового насоса) может принимать значение 1 при работоспособности агрегата, или 0 - при его отказе или принудительном простое. Выходной сигнал КМПРРС представляет собой совокупность решений по реконфигурации структуры и выбору режимов каждого из десяти измельчительных комплексов.

КМПРРС реализована на компьютере Pentium i7 с использованием языка $\mathrm{C}++$. Среднее время принятия решения для одной ситуации с помощью КМПРРС составляет около 1 мин, что позволяет

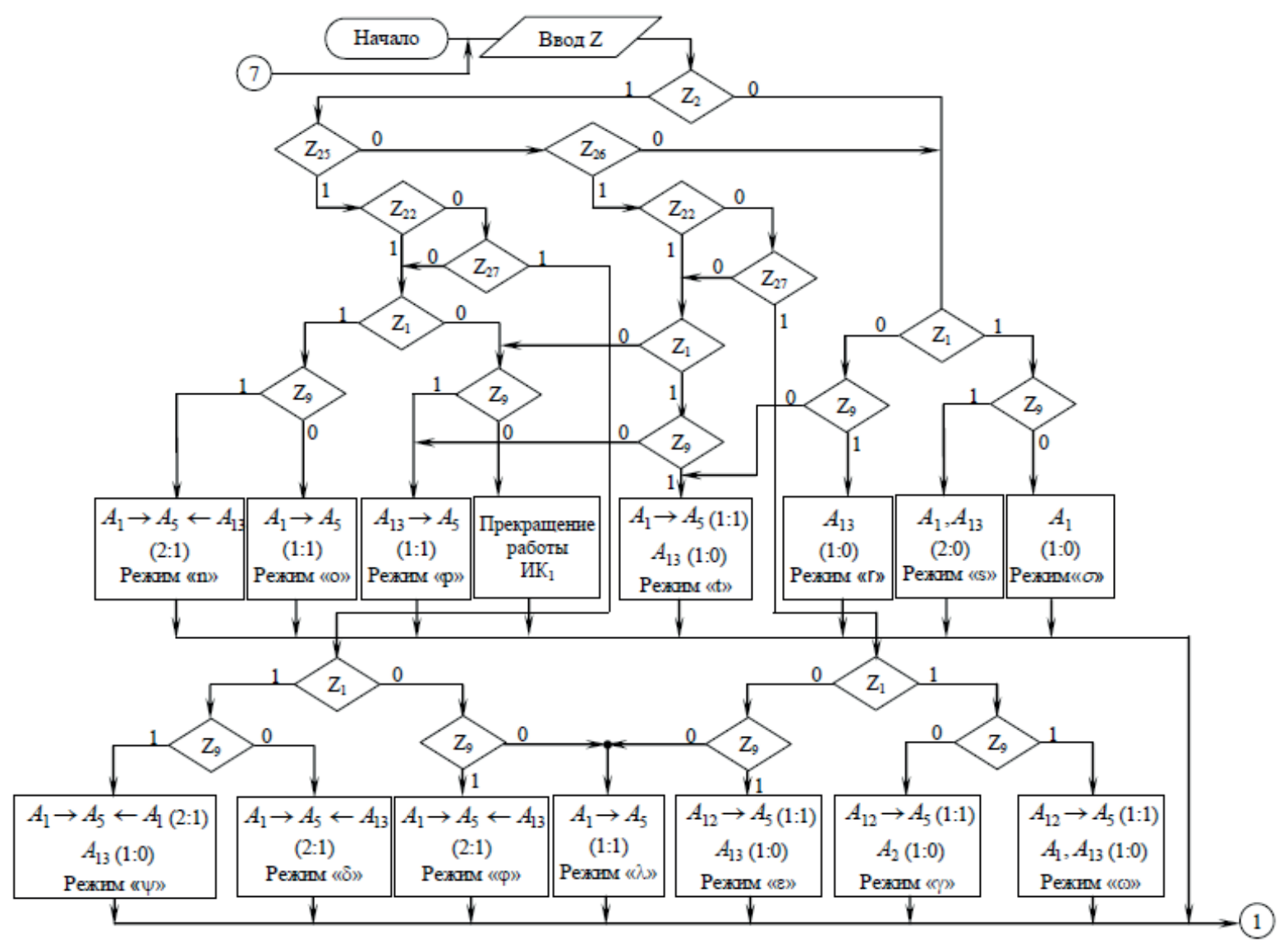

Puc. 5. Блок-схема модуля КМППРС для ИК

Fig. 5. Block diagram of computer model of decision-making system (CMDMS) module for $G_{1}$ 
использовать ее с целью управления процессом реконфигурации структуры ТСИР в реальном масштабе времени.

\section{Заключение}

Обоснована необходимость повышения надежности и эффективности функционирования ТСИР путем введения в систему структурной избыточности.

В результате имитационных экспериментов с компьютерной модели ТСИР определены наилучшая структура резервных связей между измельчительными агрегатами и рациональная стратегия реконфигурации структуры системы при отказах ее оборудовании.

На основании вышеуказанных результатов построена математическая модель принятия решений по реконфигурации структуры ТСИР при отка-

\section{СПИСОК ЛИТЕРАТУРЫ}

1. Авдохин В.М. Основы обогащения полезных ископаемых. Т. 1. Обогатительные процессы. - М.: Изд-во «Горная книга», 2014. -417 c.

2. King R.P. Modeling and Simulation of Mineral Processing Systems. $2^{\text {nd }}$ ed. - Boston: Butterworth-Heinemann, 2015. - $416 \mathrm{p}$.

3. Castro S., Lopez-Valdivieso A., Laskowski J.S. Review of the flotation of molybdenite / International Journal of Mineral Processing. - 2016. - V. 148. - P. 48-58.

4. Jovanović I., Miljanovic I. Contemporary advanced control techniques for flotation plants with mechanical flotation cells - a review // Minerals Engineering. - 2015. - V. 70. - P. 228-249.

5. Карепов В.А., Безверхая Е.В., Чесноков В.Т. Надежность горных машин и оборудования. - Красноярск: Изд-во СФУ, 2012. $-134 \mathrm{c}$.

6. Баласанян С.Ш Метод стратифицированной формализации сложных технологических систем со многими состояниями // Известия Томского политехнического университета. Инжиниринг георесурсов. - 2016. - Т. 327. - № 1. -С. 6-18.

7. Баласанян С.Ш. Стратифицированное моделирование сложных технологических систем. - Саарбрукен, Германия: LAP Lambert Academic Publishing, 2016. -385 c.

8. Баласанян С.Ш., Геворгян Э.М. Имитационная модель процесса изменения работоспособности измельчительного оборудования // Известия Томского политехнического университета. Инжиниринг георесурсов. - 2016. - Т. 327. - № 2. - С. 21-34.

9. Баласанян С.Ш., Симонян С.О., Геворгян Э.М. Компьютерная модель для стохастического управления технологическим процессом флотации руды с учетом надежности измельчительного оборудования / Известия Томского политехнического университета. - 2013. - Т. 323. - № 5. - С. 50-57.

10. Fangfang Yuan, Fusheng Lian, Xingjian Xu. Decision tree algorithm optimization research based on MapReduce $/ / 6^{\text {th }}$ IEEE International Conference on Software Engineering and Service Science (ICSESS). - Beijing, China, 23-25 Sept. 2015. P. $1010-1013$ зах ее оборудования в виде дерева решений, с использованием которой разработана компьютерная модель принятия решений по реконфигурации структуры ТСИР. Данная модель позволяет при изменении работоспособности измельчительного оборудования ТСИР своевременно выбрать наилучшую для данной отказовой ситуации структуру и режим работы каждого измельчительного комплекса, независимо от квалификации и опыта оператора. Благодаря применению этой модели оператор по существу освобождается от обязанностей лица, принимающего решения по реконфигурации структуры ТСИР при отказах ее оборудования.

Разработанная компьютерная модель включена в состав специального программного обеспечения автоматизированной системы управления технологическим процессом измельчения медно-молибденовой руды ЗММК.

11. Jani Ritika. Research on data mining classification // Int. J. Adv. Res. Comput. Sci. Software Engineering. - 2014. - 4 (4). P. 329-332.

12. Auret L., Aldrich C. Interpretation of nonlinear relationships between process variables by use of random forests // Miner. Eng. - 2012. - № 35. - P. 27-42.

13. Jani Ritika, Bhatt Nirav, Shah Chandni. A Survey on Issues of Data Stream Mining in Classification // II International Conference on Information and Communication Technology for Intelligent Systems (ICTIS 2017). - Ahmedabad, India, 25-26 March, 2017. - V. 1. - P. 137-144.

14. Turunen E., Raivio K., Mantere T. Soft Computing Methods // Mathematical Modelling / Ed. by S. Pohjolainen. - Cham, Switzerland: Springer, 2016. - P. 79-112.

15. Maimon 0., Rokach L. Data Mining and Knowledge Discovery Handbook. $2^{\text {nd }}$ ed. - New York: Springer, 2010. - 1306 p.

16. Auret L., Aldrich C. Monitoring of mineral processing operations based on multivariate similarity indices // Preprints of the $18^{\text {th }}$ IFAC World Congress. - Milano, Italy, August 28 - September 2, 2011. - P. 9923-9928.

17. Jovanovic̉ I., Miljanovic̉ I., Jovanovic̉ T. Soft computing-based modeling of flotation processes - a review // Minerals Engineering. -2015 . - V. 84. - P. 34-63.

18. Using data mining to assess and model the metallurgical efficiency of a copper concentrator / M., Massinaei M.R. Sedaghati, R. Rezvani., A.A Mohammadzadeh. // Chem. Eng. Commun. 2014. - № 201 (10). - P. 1314-1326.

19. Jahedsaravani A., Marhaban M.H., Massinaei M. Application of statistical and intelligent techniques for modeling of metallurgical performance of a batch flotation process // Chem. Eng. Commun. - 2016. - V. 203. - Iss. 2. - P. 151-160.

20. Gouws F.S., Aldrich C. Rule-based characterization of industrial flotation processes with inductive techniques and genetic algorithms // Ind. Eng. Chem. Res. - 1996. - № 35. - P. 4119-4127.

Поступила 20.04.2018 г.

\section{Информация об авторах}

Баласанян С.Ш., доктор технических наук, профессор, заместитель директора по научной работе Капанского филиала Национального политехнического университета Армении.

Геворгян Э.М., кандидат технических наук, ассистент кафедры информационных технологий, информатики и автоматизированных систем Капанского филиала Национального политехнического университета Армении. 
UDC 681.51:622.73

\title{
COMPUTER MODEL OF DECISION-MAKING ON RECONFIGURATION OF THE ORE GRINDING TECHNOLOGICAL SYSTEM STRUCTURE
}

\author{
Seyran Sh. Balasanyan', \\ seyran@sunicom.net \\ Hermine M. Gevorgyan', \\ hermine79@rambler.ru \\ ${ }^{1}$ Kapan branch of National Polytechnic University of Armenia, \\ 28, Baghaberd Street, Kapan, 3307, Armenia.
}

The relevance of the research is caused by the need to improve the reliability and efficiency of functioning of the ore grinding technological system by introducing structural redundancy.

The main aim of the research is to substantiate the need to improve the efficiency of the ore grinding technological system by introducing structural redundancy (reserve links), determining the best structure of reserve connections between grinding aggregates and rational strategies for their use, building a mathematical decision-making model for reconfiguring the structure of the ore grinding technological system at the failure of its equipment in the form of a decision tree, the development of a decision-making computer model for reconfiguring the ore grinding technological system structure.

Object of the research is the ore grinding technological system of Zangezur Copper-Molybdenum Combine (Armenia).

Methods: decision-tree method (method soft computing), simulation modeling.

The result of simulation experiments with the computer model of the technological system of ore grinding is determined by the best structure of the redundant links between the milling units and rational strategy for their use, on the basis of which the authors have developed a mathematical model of decision-making on reconfiguring the structure of ore grinding technological system (at the failure of its equipment) in the form of a decision tree. On the basis of this model the authors developed a computer model that allows, with a change in the operability of grinding aggregates, selecting in a timely manner the best structure of the redundant links and mode of operation for each unit for the current failed situation, regardless of the operator's skills and experience. Thanks to the application of this model, the operator is completely freed from the duties of the decision-maker. The developed computer model was included in the special software of the automated process control system for grinding the ore from Zangezur Copper-Molybdenum Combine.

Key words:

Ore grinding, failure, simulation modeling, decision tree, reconfiguration, structural redundancy.

\section{REFERENCES}

1. Avdokhin V.M. Osnovy obogashcheniya poleznykh iskopaemykh. T. 1. Obogatitelnye protsessy [The fundamentals of mineral processing. Vol. 1. Mineral processing]. Moscow, Gornaya kniga Publ., 2014. $417 \mathrm{p}$.

2. King R.P. Modeling and Simulation of Mineral Processing Systems. $2^{\text {nd }}$ ed. Boston, Butterworth-Heinemann, 2015. 416 p.

3. Castro S., Lopez-Valdivieso A., Laskowski J.S. Review of the flotation of molybdenite. International Journal of Mineral Processing, 2016, vol. 148, pp. 48-58.

4. Jovanović I., Miljanović I. Contemporary advanced control techniques for flotation plants with mechanical flotation cells - a review. Minerals Engineering, 2015, vol. 70, pp. 228-249.

5. Karepov V.A., Bezverkhaya E.V., Chesnokov V.T. Nadezhnost gornykh mashin i oborudovaniya [Reliability of mining machines and equipment]. Krasnoyarsk, SFU Publ., 2012.134 p.

6. Balasanyan S.Sh A stratified method of formalization of multistate complex technological systems. Bulletin of the Tomsk Polytechnic University. Geo Assets Engineering, 2016, vol. 327, no. 1, pp. 6-18. In Rus.

7. Balasanyan S.Sh. Stratifitsirovannoe modelirovanie slozhnykh tekhnologicheskikh sistem [Stratified modeling of complex technological systems]. Saarbrucken, Germany, LAP Lambert Academic Publishing, 2016. 385 p.

8. Balasanyan S.Sh., Gevorgyan H.M. Simulation model of changing working capacity of grinding equipment. Bulletin of the Tomsk Polytechnic University. Geo Assets Engineering, 2016, vol. 327, no. 2, pp 21-34. In Rus.

9. Balasanyan S.Sh, Simonyan S.0., Gevorgyan H.M. Computer model for stochastic control of ore flotation considering grinding equipment reliability. Bulletin of the Tomsk Polytechnic University, 2013, vol. 323, no. 5, pp. 50-57. In Rus.

10. Fangfang Yuan, Fusheng Lian, Xingjian Xu. Decision tree algorithm optimization research based on MapReduce. $6^{\text {th }}$ IEEE International Conference on Software Engineering and Service Science (ICSESS). Beijing, China, 23-25 September, 2015. pp. 1010-1013.

11. Jani Ritika. Research on data mining classification. Int. J. Adv. Res. Comput. Sci. Software Engineering, 2014, no. 4 (4), pp. 329-332.

12. Auret L., Aldrich C. Interpretation of nonlinear relationships between process variables by use of random forests. Minerals Engineering, 2012, no. 35, pp. 27-42.

13. Jani Ritika, Bhatt Nirav, Shah Chandni. A Survey on Issues of Data Stream Mining in Classification. II International Conference on Information and Communication Technology for Intelligent Systems (ICTIS 2017). Ahmedabad, India, 25-26 March, 2017. Vol. 1, pp. 137-144.

14. Turunen E., Raivio K., Mantere T. Soft Computing Methods. Mathematical Modelling. Ed. by S. Pohjolainen. Cham, Switzerland, Springer, 2016. pp. 79-112.

15. Maimon 0., Rokach L. Data Mining and Knowledge Discovery Handbook. $2^{\text {nd }}$ ed. New York, Springer, 2010. 1306 p.

16. Auret L., Aldrich C. Monitoring of mineral processing operations based on multivariate similarity indices. Preprints of the $18^{\text {th }}$ IFAC World Congress. Milano, Italy, 2011, August 28 - September 2. pp. 9923-9928.

17. Jovanovic I., Miljanovic I., Jovanovic T. Soft computing-based modeling of flotation processes - a review. Minerals Engineering, 2015, vol. 84, pp. 34-63. 
18. Massinaei M., Sedaghati M.R., Rezvani R., Mohammadzadeh A.A. Using data mining to assess and model the metallurgical efficiency of a copper concentrator. Chem. Eng. Commun., 2014, no. 201 (10), pp. 1314-1326.

19. Jahedsaravani A., Marhaban M.H., Massinaei M. Application of statistical and intelligent techniques for modeling of metallurgi- cal performance of a batch flotation process. Chem. Eng. Commun., 2016, vol. 203, no. 2, pp. 151-160.

20. Gouws F.S., Aldrich C. Rule-based characterization of industrial flotation processes with inductive techniques and genetic algorithms. Ind. Eng. Chem. Res., 1996, no. 35, pp. 4119-4127.

Received: 20 April 2018.

\section{Information about the authors}

Seyran Sh. Balasanyan, Dr. Sc., professor, deputy director on research works, Kapan branch of National Polytechnic University of Armenia.

Hermine M. Gevorgyan, Cand. Sc., assistant, Kapan branch of National Polytechnic University of Armenia. 